\title{
Propagação vegetativa de Peltodon rugosus por meio de xilopódios ${ }^{(1)}$
}

\author{
ANGELINE MARTINI(2), DANIELA BIONDI(3), CAMILA MARIA NATAL ${ }^{(4)}$, LUCIANA LEAL $^{(4)}$
}

\begin{abstract}
RESUMO
Peltodon rugosus Tolm. (Lamiaceae), espécie herbácea nativa do Brasil, pertencente ao ecossistema de Campos, apresenta grande potencial ornamental. Para viabilizar seu uso no mercado, o presente estudo teve como objetivo testar a propagação vegetativa de Peltodon rugosus em diferentes estações do ano. As matrizes para os experimentos foram coletadas no Campus III da Universidade Federal do Paraná, Curitiba, Paraná, nos meses de fevereiro, junho, agosto e dezembro de 2008. O experimento foi instalado em delineamento inteiramente casualizado, em esquema fatorial 4 x 2, com quatro estações do ano e duas secções do xilopódio (com folha e sem folha). Como leito de enraizamento foi utilizada uma bandeja de plástico branco $(50 \mathrm{~cm} \times 35 \mathrm{~cm} 10 \mathrm{~cm})$ preenchida com vermiculita. Esse recipiente foi mantido em ripado, coberto com sombrite $50 \%$ e umedecido com regador diariamente até a saturação de umidade no substrato. A avaliação ocorreu 90 dias após o plantio e as variáveis analisadas foram: percentagem de xilopódios enraizados, vivos e mortos; número de raízes por xilopódio; número e comprimento das brotações em cada xilopódio. A análise estatística foi feita pelo teste SNK a 95\% de probabilidade. Considerou-se que a porção do xilopódio, com ou sem folha, não é um fator que afeta esta forma de propagação. O experimento implantado no inverno apresentou os menores percentuais de enraizamento (36,85 \%). Nas demais estações do ano, não foram verificadas diferenças estatísticas para esta variável, pois todas apresentaram índices de enraizamento superior a 69\%. A propagação vegetativa por meio de xilopódio mostrou-se eficiente para esta espécie na maior parte do ano. Apenas no inverno não foi encontrado um valor expressivo.
\end{abstract}

Palavras-chave: enraizamento, produção de mudas, espécie ornamental, espécie nativa.

\section{ABSTRACT}

Vegetative propagation of Peltodon rugosus using xylopodium

Peltodon rugosus Tolm. (Lamiaceae), a herbaceous Brazilian native species from the fields ecosystem has great ornamental potential. To facilitate its use in the market, this study aimed to test the propagation of Peltodon rugosus in different seasons. The matrices for the experiments were collected on the Campus III of UFPR in February, June, August and December/2008. The experiment was conducted in a completely randomized design, in factorial $4 \times 2$, with four seasons and two sections of xylopodium: with and without leaf. As rooting beds was used a white plastic trays $(50 \mathrm{~cm}$ x $35 \mathrm{~cm} 10 \mathrm{~cm})$ filled with vermiculite. This container was kept in slatted, covered with $50 \%$ shading and moistened with daily watering to saturation of moisture in the substrate. The evaluation took place 90 days after planting and the variables analyzed were: percentage of xylopodium rooted, alive and dead, number of roots by xylopodium, number and length of sprouting in each xylopodium. Statistical analysis was made by SNK test at $95 \%$ probability. It was observed that the portion of xylopodium, with or without leaves, is not a factor that affects this form of propagation. The experiment implemented in the winter had the lowest percentage of rooting (36.85\%). The other seasons did not differ statistically for this variable, because all had rates above $69 \%$ rooting. Vegetative propagation, using the xylopodium, proved to be efficient for this species in most of the year. Only in winter was not found a significant value.

Keywords: rooting, seedlings, ornamental species, native species.

\section{INTRODUÇÃO}

O elenco de espécies nativas do Brasil comercializadas no mercado de plantas ornamentais é pouco representativo diante da biodiversidade existente. Desde a época do Brasil Colonial, houve uma substituição das espécies nativas pelas exóticas, devido à falta de informações para utilização de espécies nativas em projetos paisagísticos (LEAL e BIONDI, 2006).

Segundo Fischer et al. (2007), as plantas nativas do Brasil não alcançam o mesmo prestígio no mercado nacional como as plantas exóticas trazidas desde a colonização. Conforme Leal e Biondi (2006), muitas vezes o valor das plantas nativas ornamentais só é reconhecido quando elas são estudadas e melhoradas por outros países. Os motivos relacionados a esta preferência são principalmente os de aspecto cultural, em especial no Sul do Brasil, devido à diversidade de etnias.

Para a Floricultura nacional, a inserção de novas espécies pode colaborar com o seu desenvolvimento, ampliando a oferta dos produtos disponíveis, atendendo às necessidades do mercado, desenvolvendo competitividade e estimulando a comercialização, tanto para o mercado interno como para exportação (PINTO e GRAZIANO, 2003)

Existe uma infinidade de espécies herbáceas com potencial para serem incluídas em práticas de ornamentação e paisagismo,

\footnotetext{
(1) Trabalho recebido para publicação em 06/02/2012 e aprovado em 09/06/2014

(2) Doutora em Engenharia Florestal da Universidade Federal do Paraná, Curitiba, Br. (martini.angeline@gmail.com)

(3) Professora Doutora do Departamento de Ciências Florestais da Universidade Federal do Paraná, Curitiba, Br.

${ }^{(4)}$ Mestranda em Engenharia Florestal da Universidade Federal do Paraná, Curitiba, Br
} 
mas, talvez por razões culturais ou por falta de uma visão mais ampla sobre novas e infinitas possibilidades, ervas nativas raramente são associadas, lembradas ou reconhecidas como plantas que podem ser cultivadas e apreciadas pelos brasileiros (BARROSO, 2006).

Conforme Roderjan et al.(2002), a vegetação original da cidade de Curitiba, antes da ação antrópica, era constituída por Estepe Gramíneo-Lenhosa (Campos), entremeada de agrupamentos arbóreos (com a presença de Araucárias), próximos a baixadas e riachos.

Os Campos são constituídos por formas biológicas diversas, tendo como característica marcante uma vegetação herbácea e subarbustiva (MORO e CARMO, 2007), e assim, como em outras formações vegetais, as plantas acabaram por desenvolver órgãos especializados em reserva, seja de água ou nutrientes, para viabilizarem sua própria sobrevivência. Desta forma, nestas situações, ocorrem, com certa frequência, os sistemas subterrâneos espessados (MENEZES et al., 1979).

Embora a natureza dos sistemas subterrâneos espessados seja bem diversificada, eles costumam ser denominados de maneira generalizada, xilopódios (MENEZES et al., 1979). O xilopódio é considerado como um órgão que guarda e retém certa quantidade de água, servindo de substrato relativamente úmido para seus brotos (LINDMAN e FERRI, 1974).

A ocorrência de sistemas subterrâneos gemíferos está estritamente relacionada com a sobrevivência de espécies em condições desfavoráveis do ambiente, favorecendo a regeneração dos ramos aéreos e/ou a propagação vegetativa das plantas (HAYASHI, 2003). Por isso, muitas das espécies de Campos ainda não foram totalmente dizimadas pela antropização das áreas de ocorrência natural.

A propagação vegetativa por meio de órgãos subterrâneos espessados é de grande importância na natureza, visto que muitas das espécies que os possuem não produzem sementes ou as produzem em pequena quantidade (CARVALHO, 1991).

Um dos fatores frequentemente esquecidos quando se avalia a propagação vegetativa é a influência das estações do ano no momento da coleta do material vegetal. Segundo Browse (1998), existem flutuações na capacidade das estacas de raízes para a produção de calos. Portanto, torna-se essencial saber se a planta destinada a fornecer as estacas tem respostas diferentes conforme a época do ano e, se tal efeito ocorrer, qual é a melhor época para a obtenção desses órgãos de propagação.

Uma das espécies frequentemente encontradas nas áreas de Campos antropizados e que apresenta um grande potencial ornamental é Peltodon rugosus Tolmachev (Figura 1). Espécie herbácea da família Lamiaceae, nativa do sul do Brasil, na Estepe Gramíneo lenhosa (Campos). Apresenta potencial ornamental tanto pela sua inflorescência em forma globosa quanto por suas folhas com nervuras aparente. Devido a sua rusticidade, pode ainda ser utilizada em recuperação de áreas degradadas (BIONDI et al., 2007). Martini et al. (2007) testaram a propagação desta espécie através de sementes e constataram baixa percentagem de germinação.
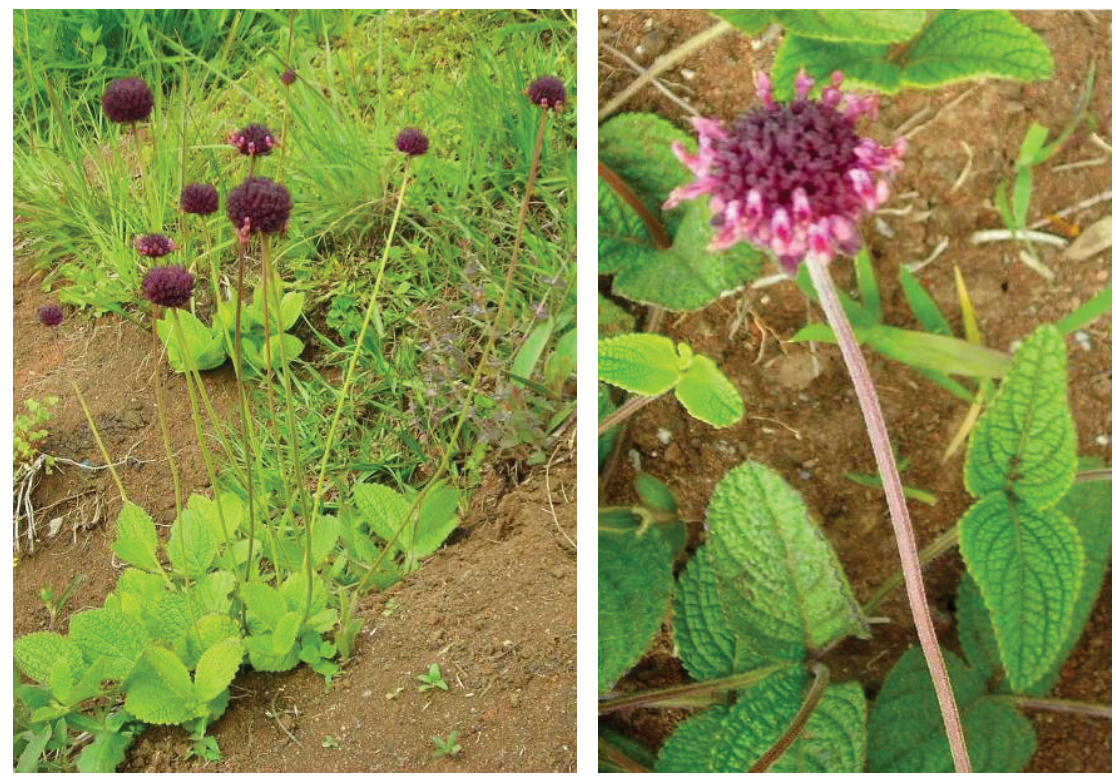

Figura 1. Exemplar de Peltodon rugosus (esquerda) e detalhe da inflorescência (direita)

Figure 1. Peltodon rugosus specimen (left) and inflorescence detail (right)

Neste contexto, o objetivo deste trabalho foi realizar a propagação vegetativa, através de xilopódios de Peltodon rugosus, em diferentes estações do ano.

\section{MATERIAL E MÉTODOS}

As matrizes para o experimento foram coletadas em área localizada no Campus III da Universidade Federal do Paraná
- UFPR (Jardim Botânico), na cidade de Curitiba-PR, situado aproximadamente a $25^{\circ} 26^{\prime} 52^{\prime \prime}$ de latitude Sul e $49^{\circ} 14^{\prime} 21^{\prime \prime}$ de longitude Oeste. A capital paranaense situa-se a uma altitude média de 908 m sobre o nível do mar. Segundo classificação de Köppen, apresenta clima do tipo $\mathrm{Cfb}$, temperado (ou subtropical) úmido, mesotérmico, sem estação seca, com verões frescos e invernos com geadas frequentes e ocasionais precipitações de neve. As médias de temperatura são de $21,11^{\circ}$ 
$\mathrm{C}$, no verão e $14,77^{\circ} \mathrm{C}$, no inverno. A precipitação média anual da cidade é de $1385,35 \mathrm{~mm}$, e a umidade média relativa do ar é de 79,3\% (IPPUC, 2008).

Os experimentos foram instalados no ano de 2008 ao final de cada estação do ano: fevereiro (verão), junho (outono), agosto (inverno), dezembro (primavera). Como material propagativo, foram utilizados xilopódios de plantas matrizes, colhidos na mesma data da instalação do experimento, escavados com auxílio de pá e enxada, seguidos por lavagem em água corrente e posteriormente seccionados. Os xilopódios foram cortados ao meio, devido a suas grandes dimensões, dividindo a parte superior, classificada como secção com folhas, da parte inferior, sem folhas. Tanto as raízes quanto as folhas existentes em ambas as partes foram eliminadas antes da instalação do experimento. As estacas de xilopódios selecionadas para a propagação apresentaram comprimento médio de $3,5 \mathrm{~cm}$ e diâmetro médio de $5,5 \mathrm{~cm}$.

$\mathrm{O}$ experimento foi instalado em delineamento inteiramente casualizado, em esquema fatorial 4 x 2, com quatro estações do ano e duas secções do xilopódio (Figura 2).
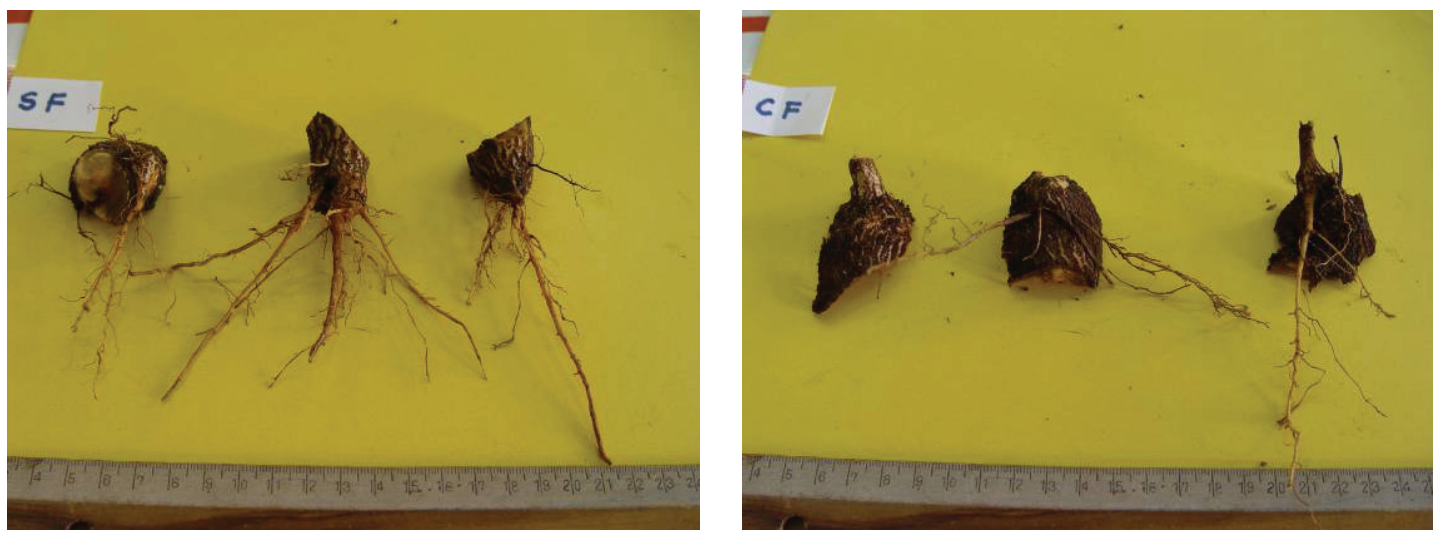

Figura 2. Secções de xilopódios para cada tratamento, à esquerda secção sem folha e à direita com folha Figure 2. Xylopodium sections for each treatment, left part without leaf and right with leaf

A quantidade de xilopódios utilizados em cada estação do ano variou devido à disponibilidade de material no campo. No verão, outono e inverno foram utilizadas três repetições de sete secções em cada tratamento e na primavera três repetições de cinco secções em cada.

Antes do plantio dos xilopódios no leito de enraizamento, foi aplicado tratamento fitossanitário com hipoclorito de sódio a $0,5 \%$ durante dez minutos no material de propagação. Como leito de enraizamento foi utilizado uma bandeja de plástico branco $(50 \mathrm{~cm} \times 35 \mathrm{~cm} 10 \mathrm{~cm})$ preenchida com vermiculita. Este recipiente foi mantido em ripado coberto com sombrite $50 \%$ e umedecido com regador diariamente até a saturação de umidade no substrato.

As variáveis analisadas foram: percentagem de xilopódios enraizados (XE), vivos não enraizados (XV) e mortos (XM); número de raízes por xilopódio (NRX) e comprimento da raiz por xilopódio $(\mathrm{CRX})$; número $(\mathrm{NB})$ e comprimento das brotações em cada xilopódio (CB).

A avaliação ocorreu 90 dias após o plantio e os dados foram submetidos à análise de variância (Teste F). Inicialmente as variâncias dos tratamentos foram avaliadas quanto a sua homogeneidade pelo teste de Bartlett. As médias foram comparadas pelo teste SNK a $95 \%$ de probabilidade somente quando se rejeitou a hipótese da nulidade.

\section{RESULTADOS E DISCUSSÃO}

A análise de variância dos dados obtidos para as variáveis percentagens de xilopódios enraizados (XE), vivos não enraizados (XV), mortos (XM), comprimento da raiz por xilopódio $(\mathrm{CRX})$, número $(\mathrm{NB})$ e comprimento das brotações em cada xilopódio (CB) revelou que a interação entre os fatores estação do ano e secção do xilopódio não foi estatisticamente significativa, o que indica que estes fatores são independentes (Tabela 1). Entretanto, a análise de variância para os outros dois fatores, número de raízes por xilopódio (NRX) e número de brotações em cada xilopódio (NB), revelou que há interação entre os fatores, o que indica que são dependentes para essas variáveis.

A interação entre os fatores estação do ano e secção do xilopódio foi estatisticamente significativa apenas para o número de raízes $(\mathrm{p}<0,01)$ e brotações $(\mathrm{p}<0,05)$ por xilopódio. Esse resultado mostra que, para essas variáveis, dependendo da estação do ano, pode ser apresentada eficiência variada entre a porção do xilopódio utilizada (com folha e sem folha). Essa interação entre os fatores evidencia a importância de se utilizar as diferentes secções do xilopódio levando em consideração as diferentes estações do ano.

Observa-se, na Tabela 1, que a análise de variância dos dados obtidos para todas as variáveis mostrou não haver diferença estatística significativa dentro do fator secção do xilopódio. Desta forma, pode-se afirmar que a porção do xilopódio utilizada não é um fator que afeta nesta forma de propagação, pois foram observadas similaridades nos resultados entre os tratamentos que se utilizaram dos xilopódios com folhas e os xilopódios sem folhas. Esse resultado permite indicar ainda que o xilopódio pode ser fragmentado em mais porções, aumentando o número de indivíduos reproduzidos de uma mesma matriz. 
Ainda com base na Tabela 1, observa-se diferença estatística dentro do fator estação do ano para todas as variáveis analisadas, com exceção da porcentagem de xilopódios mortos. Segundo Freitas (2002), a época do ano para a coleta de estacas é um fator decisivo para o sucesso do enraizamento, o que foi verificado estatisticamente neste experimento. Vale ressaltar que para a porcentagem de xilopódios mortos não foi encontrada diferença estatística significativa, pois não ocorreram mortes em nenhuma das estações e secções do xilopódio.

Tabela 1. Análise de variância (teste F) da percentagem de xilopódios enraizados (XE), número de raízes por xilopódio (NRX), comprimento da raiz por xilopódio (CRX), percentagem de xilopódios vivos (XV), percentagem de xilopódios mortos (XM), número de brotações (NB) e comprimento das brotações (CB) de Peltodon rugosus

Table 1. Analysis of variance (test $F$ ) the percentage of xylopodium rooted (XE), alive (XV) and dead (XM), number (NRX) and length (CRX) of roots by xylopodium, number (NB) and length $(C B)$ of sprouting in each xylopodium of the Peltodon rugosus

\begin{tabular}{|c|c|c|c|c|c|c|c|c|c|}
\hline Causas da variação & GL & XE (\%) & NRX & CRX $(\mathbf{c m})$ & $\mathbf{X V}(\%)$ & $\mathbf{X M}(\%)$ & NB & CB $(\mathrm{cm})$ \\
\hline Secção do xilopódio (S) & 1 & $0,989^{\text {ns }}$ & $0,227^{\text {ns }}$ & $0,288^{\text {ns }}$ & $0,439^{\text {ns }}$ & $1,000^{\text {ns }}$ & $4,054^{\text {ns }}$ & $1,588^{\text {ns }}$ \\
\hline Estações (E) & 3 & $7,221^{* *}$ & $7,270^{* *}$ & $4,149^{*}$ & $6,365^{* *}$ & $1,000^{\text {ns }}$ & $13,581^{* *}$ & $11,963^{*}$ \\
\hline Interação E x S & 3 & $0,398^{\text {ns }}$ & $6,535^{* *}$ & $2,915^{\text {ns }}$ & $0,387^{\text {ns }}$ & $1,000^{\text {ns }}$ & $4,241^{*}$ & $0,004^{\text {ns }}$ \\
\hline Erro total & 16 & & & & & & & \\
\hline Coeficiente de variação (\%) & & 27,75 & 23,99 & 32,31 & 60,60 & 489,90 & 27,77 & 54,23 \\
\hline
\end{tabular}

NOTA: ns Não significativo; * Significativo a 95\% de probabilidade; ** Significativo a $99 \%$ de probabilidade.

A comparação das médias encontradas para cada parâmetro avaliado na propagação de xilopódio de Peltodon rugosus, nas quatro estações do ano, pode ser observada na Tabela 2. Com base nesta tabela, nota-se que o experimento implantado no inverno apresentou as menores percentagens de xilopódios enraizados entre todas as estações (36,85\%), diferenciando-se dos demais tratamentos, que apresentaram valores superiores a $69 \%$. O resultado encontrado nesta estação pode estar direta ou indiretamente relacionado com o período de avaliação ter sido insuficiente, pois os xilopódios permaneceram vivos e produzindo brotações.

No outono, esta espécie apresenta alta taxa de enraizamento, embora estatisticamente junto com esta estação estejam as estações da primavera e do verão, que são estações quando se verifica maior atividade fisiológica na maioria das espécies. Este fato não é muito comum com a maioria das espécies, como pode ser visto a seguir.

Scaloppi Junior e Martins (2003), em experimento realizado com estacas caulinares de Annona glabra, encontraram maior porcentagem de enraizamento no verão (94\%) e menor no inverno (3,8\%). Já na estação do outono, foram encontradas 19,8\% de estacas enraizadas. Lima et al. (2009) também constataram maior enraizamento na estação do verão $(58,34 \%)$ para estacas de espinheira-santa, porém o menor resultado foi encontrado para a estação da primavera $(8,85 \%)$. A estação do outono apresentou enraizamento de $34,50 \%$, o que é relativamente alto se comparado às demais, sendo a segunda melhor estação para o enraizamento de espinheira santa. Por fim, Sarzi e Pivetta (2005) verificaram, em um experimento que avaliou o efeito das estações do ano no enraizamento de estacas de cinco cultivares de minirroseiras, que houve enraizamento das estacas somente na primavera e no verão.

Desta forma, constata-se que a influência das estações do ano é variável e depende da espécie. Este resultado corrobora com Campos (2010), ao afirmar que a melhor época do ano em que se deve realizar a coleta do material vegetativo varia conforme o perfil de cada espécie. Alimenta ainda mais a importância desse trabalho ao dizer que as épocas no decorrer do ano devem ser investigadas para se conhecer qual época proporcionará o melhor enraizamento.
O número de raízes por xilopódio também apresentou diferença estatística, no verão foi encontrado o melhor resultado, 4,28 raízes por xilopódio, e na primavera o menor valor, 2,26. Assim como o encontrado por Lima et al. (2009), em estacas de espinheira-santa, um número maior de raízes no verão $(6,86)$, seguido pelo outono $(5,37)$, inverno $(5,21)$ e primavera $(2,46)$. Já Scaloppi Junior e Martins (2003), encontraram maior número de raízes em estacas de Annona glabra no verão (4,1), porém o menor número foi encontrado no inverno $(0,1)$.

Quanto ao comprimento das raízes por xilopódio, verificou-se o melhor resultado novamente na estação do verão $(5,11 \mathrm{~cm})$, com diferença estatística significativa para a estação do inverno com 2,72 cm. Scaloppi Junior e Martins (2003) também encontraram esse resultado para o maior comprimento de raízes em estacas de Annona glabra. No verão, o comprimento da maior raiz foi de $7,2 \mathrm{~cm}$ o menor, no inverno, foi de $0,2 \mathrm{~cm}$. Lima et al. (2009) encontraram o maior comprimento de raiz na estação do verão $(4,71 \mathrm{~cm})$, porém na primavera é que se encontrou o menor comprimento da raiz $(3,07 \mathrm{~cm})$. Na estação do outono, os autores encontraram $4,03 \mathrm{~cm}$ de comprimento e no inverno $4,21 \mathrm{~cm}$.

No inverno também foi verificado que a percentagem de xilopódios vivos não enraizados foi maior $(63,15 \%)$, o que pode estar direta ou indiretamente relacionado com o período de avaliação ter sido insuficiente, pois os xilopódios permaneceram vivos e produzindo brotações. Não foram encontradas diferenças estatísticas entre as estações para a variável percentagem de xilopódios mortos.

O número de brotações no outono foi maior do que nos demais tratamentos $(6,82)$, mostrando-se estatisticamente distinto, embora o comprimento de suas brotações tenha sido pequeno $(5,49 \mathrm{~cm})$. Os maiores comprimentos de brotações foram encontrados na estação da primavera $(20,14 \mathrm{~cm})$ e os menores no verão $(2,56 \mathrm{~cm})$, com diferença estatística entre eles. A variável brotação pode ter influência, além das estações do ano, do tamanho do xilopódio e consequentemente da disponibilidade de reservas. Tofanelli et al. (2003), pesquisando pessegueiro cv. Okinawa, encontrou maior percentual de brotação nas estacas mais espessas, devido talvez à maior disponibilidade de reservas nas estacas com maior diâmetro, favorecendo a emissão dos brotos. 
Tabela 2. Comparação de médias para as variáveis analisadas em Peltodon rugosus, com diferentes seções de xilopódios e estações do ano

Table 2.Comparison of averages for the variable analysed at Peltodon rugosus, with different sections xilopodiuns and seasons

\begin{tabular}{|c|c|c|c|c|}
\hline \multirow{3}{*}{ Secção do xilopódio } & \multicolumn{4}{|c|}{ Estações do ano } \\
\hline & VERÃO & OUTONO & INVERNO & PRIMAVERA \\
\hline & \multicolumn{4}{|c|}{ Percentagem de xilopódios enraizados (\%) } \\
\hline Com Folha & 79,17 & 90,47 & 36,67 & 73,33 \\
\hline Sem Folha & 77,78 & 70,00 & 37,04 & 65,00 \\
\hline \multirow[t]{2}{*}{ Média } & 78,47 a & 80,24 a & 36,85 b & 69,17 a \\
\hline & \multicolumn{4}{|c|}{ Número de raízes por xilopódio } \\
\hline Com Folha & 3,99 & 4,75 & 2,13 & 2,87 \\
\hline Sem Folha & 4,57 & 2,91 & 3,98 & 1,66 \\
\hline \multirow[t]{2}{*}{ Média } & $4,28 \mathrm{a}$ & $3,83 \mathbf{a b}$ & 3,06 ab & $2,27 \mathrm{~b}$ \\
\hline & \multicolumn{4}{|c|}{ Comprimento da raiz por xilopódio $(\mathrm{cm})$} \\
\hline Com Folha & 5,12 & 6,81 & 4,16 & 2,90 \\
\hline Sem Folha & 1,17 & 6,83 & 4,07 & 3,03 \\
\hline \multirow[t]{2}{*}{ Média } & $3,14 \mathrm{~b}$ & 6,82 a & $4,11 \mathrm{~b}$ & $2,96 \mathrm{~b}$ \\
\hline & \multicolumn{4}{|c|}{ Percentagem de xilopódios vivos (\%) } \\
\hline Com Folha & 20,83 & 9,53 & 63,33 & 26,67 \\
\hline Sem Folha & 22,22 & 30,00 & 62,96 & 26,67 \\
\hline \multirow[t]{2}{*}{ Média } & $21,53 \mathrm{~b}$ & $19,76 \mathrm{~b}$ & 63,15 a & $26,67 \mathrm{~b}$ \\
\hline & \multicolumn{4}{|c|}{ Número de brotações } \\
\hline Com Folha & 6,12 & 4,33 & 2,15 & 2,85 \\
\hline Sem Folha & 4,10 & 2,94 & 3,29 & 4,06 \\
\hline \multirow[t]{2}{*}{ Média } & 5,11 a & $3,63 \mathrm{ab}$ & $2,72 \mathrm{~b}$ & $3,45 \mathrm{ab}$ \\
\hline & \multicolumn{4}{|c|}{ Comprimento das brotações $(\mathrm{cm})$} \\
\hline Com Folha & 4,12 & 6,87 & 14,71 & 21,41 \\
\hline Sem Folha & 1,01 & 4,13 & 11,55 & 18,88 \\
\hline Média & $2,56 \mathrm{c}$ & $5,50 \mathrm{c}$ & 13,13 b & 20,15 a \\
\hline
\end{tabular}

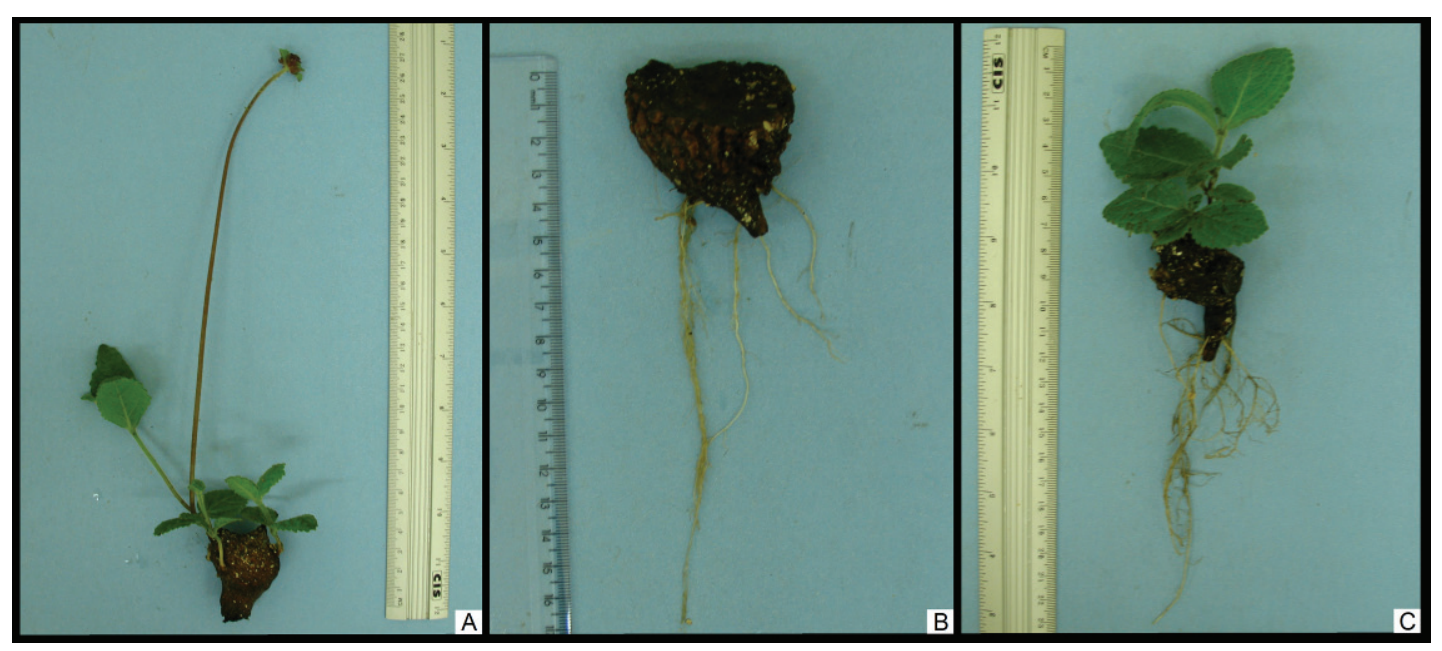

Figura 3. Xilopódio de Peltodon rugosus apresentando brotações (A), enraizamento (B) e enraizamento com brotações (C) Figure 3. Peltodon rugosus xylopodium showing the shoots $(A)$, rooting $(B)$ rooting with shoots $(C)$

Observa-se ainda, na Tabela 2, que o número e o comprimento das brotações do xilopódio não apresentaram relação com o enraizamento dos xilopódios. Em algumas espécies, o desenvolvimento da brotação na estaca pode influenciar o enraizamento. Segundo Fachinello et al. (1995), as estacas que apresentam maiores níveis de reservas favorecem o enraizamento, mas, por outro lado, podem também apresentar altas taxas de brotações desfavorecendo o enraizamento. Entretanto, observou-se que, após o período de avaliação do experimento, mesmo as estacas que apresentaram primeiro o 
surgimento de brotações acabaram enraizando, demonstrando que para a propagação por xilopódio de Peltodon rugosus o surgimento de brotações não é prejudicial. Exemplos aleatórios de xilopódios que apresentaram somente brotação, enraizamento e enraizamento com brotação podem ser observados na Figura 3.

\section{CONCLUSÃO}

A propagação vegetativa de Peltodon rugosus por meio da utilização de xilopódio se mostrou um método de propagação satisfatório na maior parte do ano, com exceção da estação do inverno. Com base em outros trabalhos já realizados, pode-se afirmar que essa forma de propagação é mais indicada já que a reprodução sexuada desta espécie apresenta baixa percentagem de germinação.

A porção do xilopódio utilizada, com ou sem folhas, não é um fator que afeta nesta forma de propagação. Desta forma, recomenda-se que, em novas pesquisas, sejam utilizadas secções do xilopódio ainda menores, buscando aperfeiçoar essa forma de propagação e aumentar sua eficiência. Além de se realizar novos estudos para analisar exclusivamente a interação entre as estações do ano e a secção do xilopódio para as variáveis número de brotações e comprimento das raízes.

\section{REFERÊNCIAS}

BARROSO, C.M. Propagação de espécies nativas com potencial ornamental. Porto Alegre, 2006, 212 f. Dissertação (Mestrado em Fitotecnia) - Universidade Federal do Rio Grande do Sul.

BIONDI, D.; LEAL, L.; BATISTA, A.C.; BALENSIEFER, M. Indicación de especies nativas para la recuperación de áreas degradadas. In: SIMPÓSIO INTERNACIONAL SOBRE RESTAURACIÓN ECOLÓGICA, 2º, 2007 , Santa Clara Cuba. Anais... Santa Clara - Cuba, 2007.

BROWSE, P. M. A propagação das plantas. Trad. Sob a edição de Francisco Lyon de Castro. 4. ed. Lisboa: Publicações Europa-América, 1998. 228p. (Coleção EUROAGRO Enciclopédia de Práticas Agrícolas).

CAMPOS, G.N.F. Clonagem de Cnidoscolus Phyllacanthus (Mart.) Pax et K. Hoffm. (faveleira) por alporquia. Patos - PB, 2010, 45 f. Dissertação (Mestrado em Ciências Florestais) Universidade Federal de Campina Grande.

CARVALHO, M.A.M. Variações no conteúdo e na composição de frutanos em rizóforos de Vernonia herbacea (Vell.) Rusby. Campinas, 1991, 119f. Tese (Doutorado em Ciências) - Instituto de Biologia da Universidade Estadual de Campinas.

FACHINELLO, J.C.; HOFFMANN, A.; NACHTIGAL, J.C.; KERS, E.; FORTES, G.R.L. Propagação de plantas frutíferas de clima temperado. Pelotas: UFPEL, 1995.
FISCHER, S. Z.; STUMPF, E.R.T.; HEIDEN, G.; BARBIERI, R.L.; WASUM, R.A. Plantas da flora brasileira no mercado internacional de floricultura. Revista Brasileira de Biociências, Porto Alegre, v.5, supl. 1, p.510-512, 2007.

FREITAS, M.I.C. Propagação Vegetativa de Sobreiros Seleccionados. Silva Lusitana, Lisboa, v.10, n.1, p.17-52, 2002.

HAYASHI, A.H. Morfo-anatomia de sistemas subterrâneos de espécies herbáceo-subarbustivas e arbóreas, enfatizando a origem das gemas caulinares. Campinas, 2003, $154 \mathrm{f}$. Tese (Doutorado em Biologia Vegetal) - Instituto de Biologia da Universidade Estadual de Campinas.

IPPUC - Instituto de Pesquisa e Planejamento Urbano de Curitiba. Curitiba em dados-2008. Disponível em: $<\underline{\text { http: } / /}$ ippucnet.ippuc.org.br/bancodedados/curitibaemdados/ curitibaemdados_pesquisa.asp > Acesso em: 23 fevereiro 2008.

LEAL, L.; BIONDI, D. Potencial ornamental de espécies nativas. Revista Científica Eletrônica de Engenharia Florestal, Garça, n.8, p.1-16. 2006.

LIMA, D.M. de; BIASI, L.A.; ZANETTE, F.; ZUFFELLATORIBAS, K.C. Estaquia e caracterização anatômica de espinheirasanta em cada estação do ano. Anais... III Seminário: Sistemas de Produção Agropecuária. UTFPR: Dois Vizinhos, 2009.

LINDMAN, C.A. M.; FERRI, M.G. A Vegetação no Rio Grande do Sul. Belo Horizonte. Ed. Itatiaia; São Paulo. Ed. da Universidade de São Paulo. p.157-160, 1974.

MARTINI, A.; NATAL, C.M.; BIONDI, D.; LEAL, L. Propagação por sementes de Peltodon rugosus: uma planta nativa com potencial ornamental. In: CONGRESSO NACIONAL DE BOTANICA, 58 , 2007, São Paulo. Anais... São Paulo, 2007.

MENEZES, N.L.; MÜLlER, C.; SAJO, M.G. Um novo e peculiar tipo de sistema subterrâneo em espécies de Vernonia da Serra do Cipó (Minas Gerais, Brasil). Bol. Botânica, Univ. S. Paulo, v.7, n.1, p.33-38, 1979.

MORO, R.S.; CARMO, M.R.B. do. A vegetação campestre nos Campos Gerais. In: MELO, M. S.; MORO, R. S.; GUimarães, G. B. Patrimônio natural dos Campos Gerais do Paraná. Ponta Grossa: Editora UEPG, p.93-98, 2007.

PINTO, A.C.; GRAZIANO, T.T. Potencial ornamental de Curcuma. Revista Brasileira de Horticultura Ornamental, Campinas, v.9, n.2, p.99-109, 2003.

RODERJAN, C.V.; GALVÃO, F.; KUNIYOSHI, Y.S.; HATSCHBACH, G.G. As unidades fitogeográficas do Estado do Paraná. Ciência \& Ambiente, Santa Maria-RS, n.24, p.75-92, 2002. 
SARZI, I.; PIVETTA, K.F.L. Efeito das estações do ano e do ácido indolbutírico no enraizamento de estacas de variedades de minirroseira (Rosa spp.). Científica, Jaboticabal, v.332, n.1, p.62-68, 2005.

SCALOPPI JUNIOR, E.J.; MARTINS, A.B. Clonagem de quatro espécies e Annonaceae potenciais como portaenxertos. Revista Brasileira de Fruticultura, v.25, n.2, p. 286-289, 2003.
TOFANELLI, M.B.D.; RODRIGUES, J.D.; ONO, E.O. Enraizamento de estacas lenhosas de pessegueiro cv. Okinawa em diferentes diâmetros de ramos, substratos e recipientes. Ciência Rural, Santa Maria, v.33, n.3, p.437-442, 2003 